\title{
The landscapes of energy incentives
}

\author{
Marcello Magoni ${ }^{1^{*}}$ (D) and Roberto Adami
}

\begin{abstract}
The huge economic resources which have been available for more than a decade to promote the development of renewable energy sources (RES) and assimilated ones have had as a side effect the installation of plants in many areas of Italian territory, where, in several cases, they started to characterize the landscapes. The high speed with which these plants spread in the territory, the low consideration generally given to the landscape and the cultural and normative lack of preparation with which local authorities have been able to address this diffusion in its acute phase have triggered a strong debate - not only among experts but also in the newspapers - which was useful to understand the issue and to think about possible solutions. This article aims to describe a general framework about the principal effects on the landscape produced by economic incentives in the energy sector, reflecting on the main phases in which economic resources have been allocated to stimulate the use of RES. The first part of the essay describes the incentive mechanisms of RES which have been adopted in Italy since the early 1980s, with particular attention to those adopted during this decade, since these latter have been much more effective and have had a greater impact on the landscape. In the second part the technological, building and territorial factors which are causing the incentives for RES plants to significantly affect the landscape of some territories will be illustrated (see for example those areas affected by wind farms or biogas and photovoltaic plants). Following such line of reasoning we can talk about landscapes of energy incentives. In the third part the main changes to the landscape due to medium and large wind power, photovoltaic, hydroelectric and biomass plants will be summarized.
\end{abstract}

Keywords: Landscapes of energy, Energy incentives, Renewable energy plants

\section{Incentives to renewable energy sources: a non-linear strategy}

In the major European countries the issue regarding the support mechanisms for renewable energy sources plants (RES plants) has been addressed in various ways, mainly considering three types of interventions which are the feed-in tariffs, the Green Energy Production Certificates mechanisms and the tax breaks. ${ }^{1}$

The first consists in favoured fees for the production and sales to the grid of energy produced by RES, the second defines the obligation to use, sell or produce certain amounts of RES energy while the third allows for direct loans and tax breaks for the development of new plants. Within all these various types of incentives, mechanisms have been proposed and altered or occasionally cancelled due to both a change in the economic situation and the need to find procedures that can be more operator-friendly and less expensive for public authorities to review the incentive requests.

In Italy, support mechanisms were introduced in 1982 with the 308/82 Law, which included incentives for feasibility studies and the development of both RES plants and RES-assimilated plants. Among the RES plants, the ones powered by sunlight, wind, water, geothermal heat, waves, waste and vegetable products were considered for incentivization, whereas the RES-assimilated plants included those using heat recovered from electric power production and exhaust fumes from heat plants and factories. Since the early ' $90 \mathrm{~s}$ the actions to develop more and more RES plants have been gaining momentum, through the liberalization of electric energy production and the strengthening of support mechanisms. In that

*Correspondence: marcello.magoni@polimi.it

${ }^{1}$ CCRR-Lab, DAStU_-Politecnico di Milano, Milan, Italy

Full list of author information is available at the end of the article

\footnotetext{
1 This topic has been examined in a research carried on by the electrical services operator on Italy, Spain, Germany, France and United Kingdom (see Ardolino 2009).
} 
period incentives shifted to discounted fees for energy sales to the grid, considering the impact of additional costs for energy production due to the use of new RESrelated technologies (tariffs based on plant type). ${ }^{2}$ This kind of incentive, the so called CIP6/92, has been widely requested, causing significant costs to the public authority. This led to a limitation to the request of CIP6/92 subsidy and the need for less onerous support mechanisms. ${ }^{3}$ On the other hand, this limitation was requested also because most of the available funds were allocated to RES-assimilated plants, implying that more innovative and less polluting technologies were disadvantaged. ${ }^{4}$

In 1999, the Legislative Decree 79/99 introduced the green energy production certificates (green certificates) that forced energy suppliers and importers to include a percentage attributable to renewable energy sources. This percentage increases on an annual basis and could be either directly produced or bought from other suppliers. Such a mechanism generated a new 'virtual' market for renewable energies, whose costs were mostly upon the suppliers who were not switching to RES production. This type of mechanism also gives an additional revenue for the energy input to the general network, which continues even after the end of the incentive period. With the Decree 79/99, RES-assimilated plants entitled to incentives have been partially decreased, ${ }^{5}$ adding also the obligation to be officially registered as a RES plant by the electrical services operator (GSE) and thus to receive the subsidy. Only those plants harnessing wind, solar, geothermal, wave and tidal power, hydropower, biomass (as far as the biodegradable part is concerned), landfill gas, sewage treatment plant gas and biogas energy sources have been considered. The possibility to buy the so called 'green' energy also from abroad (cheaper than the green certificates released in Italy) has contributed to reduce the effectiveness of this mechanism. For the same reason, it has also become difficult to check and monitor how the imported energy has been effectively produced in the country of origin. ${ }^{6}$

\footnotetext{
2 Provvedimento del Comitato Interministeriale Prezzi No. 6, 29th April 1992.

3 Ministerial Decree of 24th January 1997.

4 Based on the analysis carried out by GSE-FISE-ASSOAMBIENTE, in 2006 about the $90 \%$ of the subsidy to renewable energies has been assigned to RES-assimilated plants.

5 Only waste-to-energy plants (using biodegradable waste), cogeneration plants combined with district heating and co-combustion plants have been considered as RES-assimilated plants.

${ }^{6}$ http://www.qualenergia.it/articoli/20101129-il-trucchetto-della-falsa -energia-verde-importata. Article of 29th November 2010 (last accessed: August 2015).
}

At the beginning of the 2000s photovoltaic plants became more and more common, relying on a consolidated know-how. To promote the growth of small photovoltaic plants, the Legislative Decree 387/2003 introduced the first energy account. This type of mechanism, based on feed-in tariffs lasting over 20 years, changed the typology of the subsidy into a supporting intervention reducing the costs that companies are holding for energy production management needs. Following the same logic, in 2008 the so called all-inclusive tariff ${ }^{8}$ was introduced to extend similar benefit also to the other RES plants (not only photovoltaic). In particular, this subsidy can be seen as an alternative to the green certificates for small and medium plants up to $1 \mathrm{MW}(200 \mathrm{~kW}$ for wind plants) that can be entitled to steady favoured fees for 15 years.

In the following years the energy account has changed many times, leading to (a) less bureaucracy to request and obtain the incentive, (b) increasing subsidies related to the level of integration between buildings and energy plants and (c) the extension of the subsidy activation period. According to the latest version of the energy account (the so called fifth energy account, as defined by the Ministerial Decree of 5th July 2012) the maximum amount of available subsidy has been set at 6.7 billion Euros per year. By the 6th of June 2013 this value was expended, causing this incentive system to temporary stop.

With regards to the non-photovoltaic RES, the regulation defines the subsidy in relation to both the amount of energy input into the public grid and the size of the plant (above or under $1 \mathrm{MW}$ ). In addition, the above-mentioned legislative intervention provides the possibility to be entitled to the support directly or via registration to specific lists. ${ }^{9}$ The Decree of 2012 has also modified the subsidy for thermodynamic solar plants, ${ }^{10}$ setting a limit to the total receiving surface and including these types of plants among the ones that are capitalising on the total available amount of subsidy per year for non-photovoltaic RES. ${ }^{11}$

\footnotetext{
${ }^{7}$ Acknowledgment of the EU Directive 2001/77/EC, implemented by the Ministerial Decree of 28th July 2005 and the Ministerial Decree of 6th February 2006

8 The all-inclusive tariff has been introduced by the financial law 2008 (law 244/2007).

9 See the "Activities Report" published by the energy services operator in 2013.

10 Support mechanisms for thermodynamic solar plants have been introduced by Ministerial Decree of 11th April 2008.

11 The maximum amount of available subsidy for non-photovoltaic RES was set to 5.8 billion Euros per year.
} 
Together with the subsidy for electricity production from renewable sources, in 2012 a new mechanism was introduced to support both public administrations and private citizens in developing 'clean' heat energy production as well as ameliorating the energy efficiency of building/plant. This new energy support mechanism, known as "Thermal Account", 12 is operating on both the promotion of RES and the reduction of energy consumption. It was designed to help towards the meeting of the targets defined by the national action plan (NAP) for renewable energy and the national energy efficiency action plan (EEAP).

With these legislative interventions the public authority has tried to accomplish the European laws' directive in this particular field. The support mechanism that has been introduced consists in a contribution to the costs for the upgrades carried out to improve energy efficiency, based on both the type of intervention and the increase in efficiency/production of the plant/building. This new mechanism encompasses a various number of scenarios, from the intervention on building envelopes to the upgrade, replacement and new installation of RES plants, and is in conflict with other available fiscal support by the public authorities. For this reason, it has not been requested intensively.

With regards to energy efficiency the main support mechanism is the one of the white certificates, introduced by the Ministerial Decree published on the 20th of July 2004 and according to which the providers of electric energy and natural gas are forced to reach a total annual amount of primary energy saving. ${ }^{13}$ Similarly to the green certificates scenario, a virtual market of energy efficiency titles $(E E T)^{14}$ has emerged, through which companies can buy or sell Certificates in order to reach the annual targets. Between 2012 and $2014^{15}$ this mechanism has been changed mainly by (a) opening the virtual market to additional stakeholders, ${ }^{16}$ (b) removing the possibility to receive this support in addition to other forms of incentive and (c) giving specific criteria to carry out energy

\footnotetext{
12 Ministerial Decree of 28th December 2012, as per Legislative Decree 28/2011.

13 Also high efficiency cogeneration plants have right to access to white certificates market as per Ministerial Decree of 5th September 2011.

14 The industry sector is significantly involved in the virtual market of energy efficiency titles, covering in 2014 the $79 \%$ of the total demand.

15 Ministerial Decree of 28th December 2012 and Legislative Decree No. $112 / 2014$.

16 Projects to obtain white certificates can be submitted by (a) providers of electrical energy and gas serving more than 50,000 clients (obligated entities), (b) their subsidiary companies, (c) not obligated providers, (d) energy services companies, (e) companies and authorities with an "energy manager" or an energy management system in compliance with ISO 50001.
}

efficiency interventions. In terms of the number of white certificates that have been exchanged, the trend has been constantly positive between 2006 and 2014. However, in terms of primary energy saving, the trend has been positive only up to 2010 and then it levelled out before starting a constant decrease in $2013 .{ }^{17}$

During 2014 significant changes have been introduced to the support mechanisms previously issued, for both photovoltaic and other renewable sources. In fact, the Decree Law 91/2014 called "Spalma Incentivi"18 has decreased the current supports as well as the possibility to obtain them in the upcoming years, considering in some cases to extend the duration of the ones already in place. These measures have led a number of stakeholders and investors, in many cases foreign, to raise legal objections to a law that is affecting ongoing agreements and investments. In the following year rules and criteria related to the "Energy Account" support have been modified, removing the limit of supports that can be requested ${ }^{19}$ and awaiting for a comprehensive intervention on the matter to be promoted by the national government. ${ }^{20}$

By the end of 2015 more than 500,000 RES plants have benefited from the energy account mechanism, up to a total installed power of $18 \mathrm{GW} .{ }^{21}$ Based on the same survey, Lombardia, Veneto and Emilia Romagna regions have the highest number of RES plants, even though Puglia region has the maximum installed power. Checking the data, about $90 \%$ of the interventions are related to medium and small scale projects (up to $20 \mathrm{~kW}$ ), mostly regarding refurbishment or renovation of existing buildings. On the other hand, the remaining $10 \%$ represents big scale projects that account for the $80 \%$ of the total installed power and also have a greater impact on the landscape. Such big scale plants (above $20 \mathrm{~kW}$ ) concentrate mostly in Northern Italy, mainly in the provinces of Cuneo and Brescia (with more than 2000 plants each), Bolzano, Milan and Verona (with more than 1600 plants each). ${ }^{22}$

\footnotetext{
${ }^{17}$ Statistics from the "annual report on white certificates" published by the energy services operator in 2014.

18 The Decree Law "Spalma Incentivi" has been implemented via the Ministerial Decree of 6th November 2014 (non photovoltaic RES) and via the Law No. 116/2014 (photovoltaic plants).

19 In the early 2015, consequently to a public consultation on this topic, it has been decided to provide strict requirements to maintain subsidies after changes or significant maintenance of the plants. After few months, these requirements and the annual limit have been suspended.

20 http://www.edilportale.com/news/2015/07/risparmio-energetico/conto -energia-cancellati-i-limiti-per-mantenere-gli-incentivi_46828_27.html (last accessed: August 2015).

21 Homepage of the energy services operator website, last update on 31st August 2015 (last accessed: September 2015).

22 http://atlasole.gse.it/atlasole/ (accessed last: August 2015).
} 


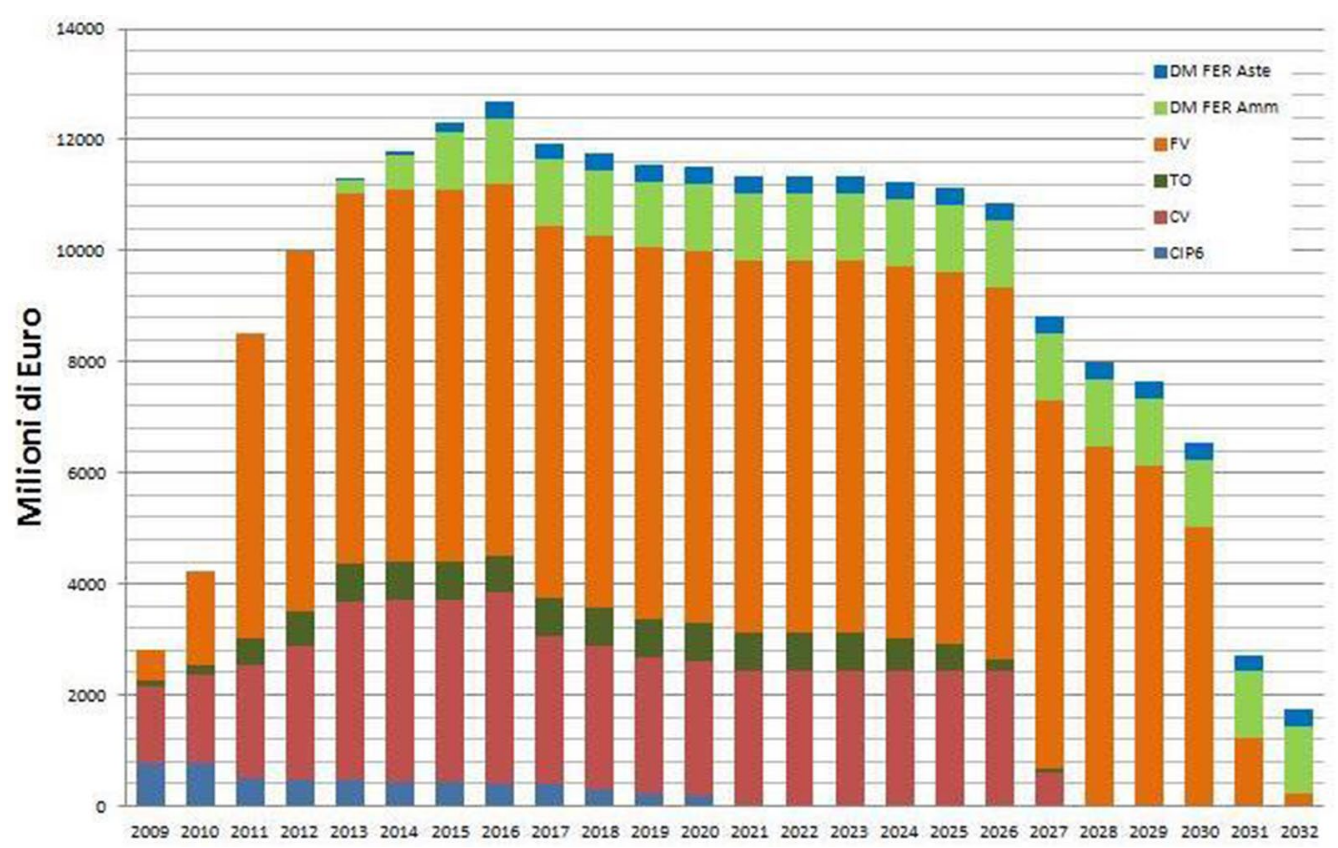

Fig. 1 Cost of support mechanisms for RES (Source: Assoelettrica on data from the energy services operator and the authority for electricity and gas)

With regards to the other RES, constantly monitored by the electrical services operator via the electrical RES counter, ${ }^{23}$ the majority of the 5.8 billion Euros per year of subsidies ${ }^{24}$ are currently distributed either via green certificates (about 50\%) or via all-inclusive tariff (about $30 \%)$. More than 7500 plants have received support up to $24.5 \mathrm{GW}$ of installed power, the $80 \%$ of which is related to the green certificates market. Hydraulic and wind plants mostly request the green certificates mechanism, whereas biogas plants are in most cases supported by the all-inclusive tariff. ${ }^{25}$

Up to 2016 the framework of the support mechanisms in Italy included various scenarios and types of subsidies, considering both the currently available ones and those mechanisms that are no longer available, but will still be effective for several years (until their expiry) for the stakeholders who had access to them when still available. ${ }^{26}$

\footnotetext{
${ }^{23}$ The electrical RES counter considers the renewable energy sources defined by the Legislative Decree 28/2011, article 2 entitled to the following support mechanisms: CIP6, green certificates, all-inclusive tariffs, energy account, subsidies as per Ministerial Decree of 6th July 2012.

${ }^{24}$ The annual limit does not include the costs for the indirect sale of energy and net metering.

${ }^{25}$ Homepage of the energy services operator website, last update 31 st of August 2015 (accessed last: September 2015).

${ }^{26}$ See the "development and monitoring of renewable energies and energy efficiency" report published by the energy services operator in 2014.
}

\section{Towards a landscape of energy incentives}

The incentives for RES plants, which have been provided in almost all developed countries, have deeply altered the energy market (Ardolino 2009) by encouraging their diffusion, prioritizing their use over fossil fuels and promoting the technological innovation and development of this industry, thus rapidly increasing their energy efficiency. Based on Assoelettrica's elaboration (see Fig. 1) the magnitude of these incentives in the period from 2009 to 2032, estimated in 2015, is around 220 billion Euros.

At the same time, over the last few years the global economic crisis has led to a large reduction of the global and national energy demand, thus halting the growth trend which had characterized the energy demand over the last 50 years. In fact, the final consumption mainly due to lower consumption rates in the industrial sector had been starting to decrease since 2006, when it reached a peak value of nearly 146 Mtep, whereas in 2014 it dropped just below 120 Mtep (see Table 1). In 2015 the negative trend was reversed as the final demand increased by about $4 \%$ over 2014, reaching nearly 125 Mtep.

In Italy, these two phenomena have led to the abolition of the construction of new fossil fuel power plants, to considerably reduce the use period of existing ones and to close the more polluting and inefficient ones. ${ }^{27}$

\footnotetext{
27 The energy company ENEL has launched a program called Futur-e (https ://corporate.enel.it/en/futur-e.html) to dispose of 23 outdated thermoelectric power plants over the next few years and make them as useful as possible in the areas where they are located. This will mean a significant improvement in the landscapes of those places.
} 
Table 1 Historical trend of final energy consumption in Italy from 2000 to 2015 (Mtep values). Source: Ministry of Economic Development, National Energy Strategy, final consumption from 1997 to 2015, historical trend

\begin{tabular}{llllll}
\hline Year & Mtep & Year & Mtep & Year & Mtep \\
\hline 2001 & 137,466 & 2006 & 145,658 & 2011 & 134,901 \\
2002 & 136,293 & 2007 & 143,211 & 2012 & 127,862 \\
2003 & 142,261 & 2008 & 141,124 & 2013 & 126,587 \\
2004 & 145,120 & 2009 & 132,705 & 2014 & 119,769 \\
2005 & 146,591 & 2010 & 138,584 & 2015 & 124,650 \\
\hline
\end{tabular}

Renewable energy plants are still growing, although less impetuously than in the previous years, and the least efficient ones are being repowered, especially wind power plants. In addition, the supply and extraction infrastructures of gas-which is considered the main fossil fuel as far as the transition towards the de-carbonization of the economy is concerned-are being strengthened as well as the connections of national and international electricity lines.

To understand the effects produced on the landscape by the process of replacing fossil fuel plants with RES plants (Socco etal. 2007 and Magoni 2010) we have to consider the surface and location of both plant types in the first place (De Pascali 2008).

Land requirement per unit of energy produced by renewable energy plants is generally much higher than that of fossil fuel plants. On the other hand, when considering the entire process of extraction, treatment, storage and transportation of fossil fuels and the plant construction, these measures tend to get closer to one another. ${ }^{28}$ However, as Italy is poor in fossil fuels and almost all of the extraction as well as much of the treatment, storage and delivery of local fossil fuels occur outside the Italian territory, the difference between the two types of plant in terms of land requirement per unit of energy produced remains broad.

\footnotetext{
${ }^{28}$ The land needed to produce a certain amount of energy from different types of plants depends on numerous factors of technological, engineering, climate, localization and infrastructure characters. Recent studies (Allred et al. 2015; Campbell et al. 2013; US Department of Energy 2015) indicate that to produce a GWh of solar electricity in the USA are occupied on average from 0.8 (for photovoltaic plants of large size in desert areas) to 3 ha (for medium-sized photovoltaic plants in less sunny areas) of land and that the land surfaces necessary to produce the totality of electricity consumed in the US in 2013 from renewable sources can be estimated in indicatively 75\% of those used in that year by non-renewable energy plants and related infrastructures, such as oil and gas well pads, storage tanks, associated roads, and pipelines.
}

The location of medium and large fossil fuel plants concerns especially the flat areas and in particular those near the watercourses. On the contrary, some types of RES plants tend to be located in areas of higher landscape interest (see hydroelectric and wind power plants) and in some cases in very visible areas (see the crests of reliefs for wind power plants) while photovoltaic systems are mainly located in flat agricultural areas.

From a visual point of view fossil fuel plants are generally the most impacting ones, although in some cases they can become landmarks. Nevertheless, it is true for every kind of plant that a good location and a welldevised design can reduce its negative impact on the landscape and often turn it into a means of landscape characterization.

A separate discourse relates to power lines, which are very visible and affect all types of territory, from mountains to flats. They serve all power generation plants, although they are now undergoing a strong upgrading and diffusion process aimed at meeting above all the interconnection needs of RES plants in order to balance their intermittent energy production.

The effects of RES plants on the landscape (Battistella 2010a, b; Manna et al. 2010; Marchigiani and Prestamburgo 2010; Serra 2011) are a function of three plant categories.

To the first category belong the existing RES plants that have received funding to recover energy waste or to increase their energy efficiency. The interventions are made on the respective sites and energy infrastructures. In these cases, the effects on the landscape have generally been minimal and have occasionally led to positive changes, since plant improvement further enhanced the design of energy equipment and buildings.

To the second category belong those installations integrated in buildings and infrastructures, as well as small and medium self-production or local production plants. These installations are often directly connected to the user, so they do not need to be supported by energy transmission and distribution infrastructures. Hence they do not have a significant impact on the landscape, except when they are placed in high historical and architectural contexts.

The main changes to the landscape are due to the third category of RES plants, such as medium and large biogas, biomass, wind, photovoltaic and hydroelectric plants. For this reason, these plant types will be synthetically described in the next section.

\section{The characters of energy landscapes of the incentive}

The main types of medium and large RES plants are wind, photovoltaic, hydroelectric, biogas and biomass plants. 


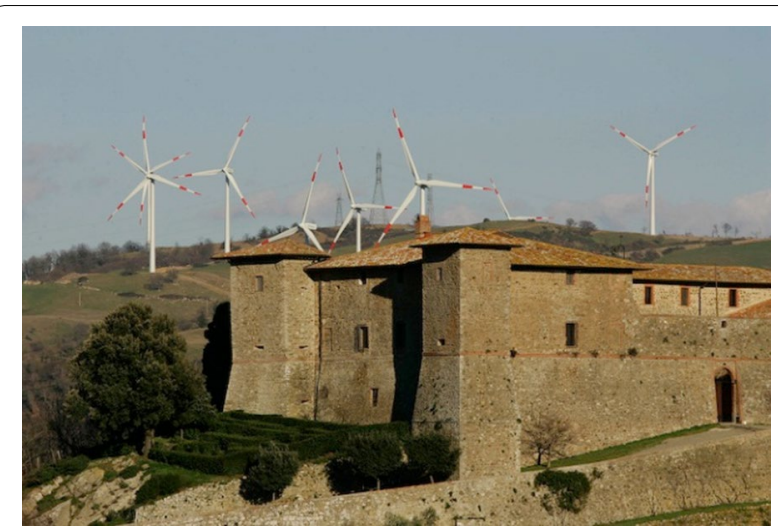

Fig. 2 Wind power plant in Poggi Alti, Scansano (GR) (Source: reteresistenzacrinali)

Wind farms produce significant effects on the landscape, due to their large size and the need to place the turbines on the ridges of reliefs to fully exploit the scarce winds blowing on most parts of Italy (Battistella 2010b). Thus they modify the skyline of large areas and their signs often emerge excessively as compared to existing elements measuring less than $15-20 \mathrm{~m}$ in height. As they are very visible, they produce the greatest impact on landscapes characterized by elements of high naturalistic, environmental, historical and architectural interest and especially by a marked identity. In addition, their light colour is very evident in areas where vegetation, stone and brick tones prevail (see Fig. 2).

On the other hand, areas with lower landscape quality are not only more suitable to receive these plants, but they often benefit from their presence as they receive new identities. In fact, the vertical lines of the turbines placed on wide and cultivated plains tend to emphasize the horizontal lines drawn by the flat territories, and where there are no emerging elements they are not perceived as intrusive and off-scale elements (see Fig. 3). In addition, in these territories the turbines' steel materials and white colour stand out against green-ochre-brown surfaces only from an aerial perspective. As a consequence, the observer perceives them having the sky as a background, which makes the chromatic impact irrelevant.

In Italy off-shore wind plants have not been built yet. In this regard, projects have been submitted but they face strong opposition from some groups of inhabitants. These plants produce a strong effect on the imagined landscape as they generally have a long-distance visual relationship with the coast, where perception is very difficult or impossible. They are not out of scale because the sea surface is flat and undifferentiated to the horizon, so that any dimensional comparison between the turbines and other elements of the

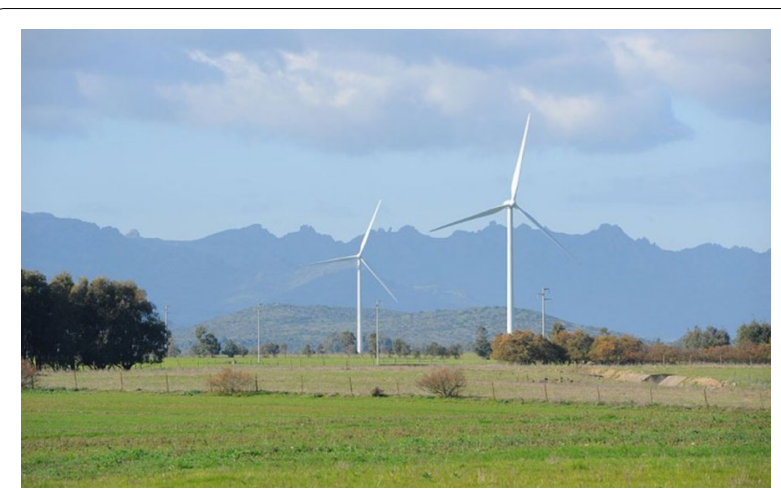

Fig. 3 Wind power plant in Villacidro (SU) (Source: villacidro.info)

landscape disappears. In addition, the turbines' steel materials and white colours seamlessly integrate into the tints of the sky and the sea, to the point that it is very difficult to catch them on the water surface unless the observer is on a helicopter or a boat. In fact, the only activities with which off-shore facilities interfere are fishing and tourism.

The ground-based photovoltaic systems have been produced in very large numbers and different sizes and have generated the most significant impact on the landscape, mainly due to the intrusiveness of their colours, materials and, as far as larger systems are concerned, dimension (Baldescu and Barion 2011). They have been placed in rural flat areas because of the wide open spaces such areas provide, which made them very visible as a result of the panels' blue-coloured silicon standing out among the tints of crops and farm buildings. It has been observed that such plants better integrate into industrial areas, where the panels' colours and materials blend easily.

In recent years the plants have been built using steel supports instead of concrete plinths to facilitate their dismantling at the end of their productive life. Moreover, in order to use the soil occupied by the plants for agricultural production, a particular category of plants has been designed and labelled with the term "agrophotovoltaic" (see Fig. 4), in which modules are placed in such a way as to allow sunlight to reach the crops below. Since landscape profiles are not altered and the dimensions are generally quite limited, the impact of these plants on the landscape is similar to that of traditional photovoltaic systems but of greater intensity, because the panels are placed at a greater height. An analogous effect on the landscape is produced by photovoltaic greenhouses (see Fig. 5) which do not involve any change in the landscape when replacing existing greenhouses, but worsen its features when they are built ex-novo. 


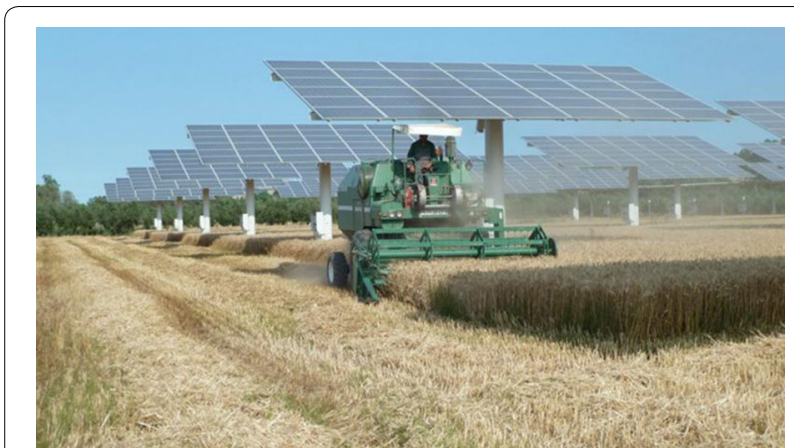

Fig. 4 Agro-photovoltaic plant in Pagliare di Morro d'Oro (TE) (Source: Corditec)

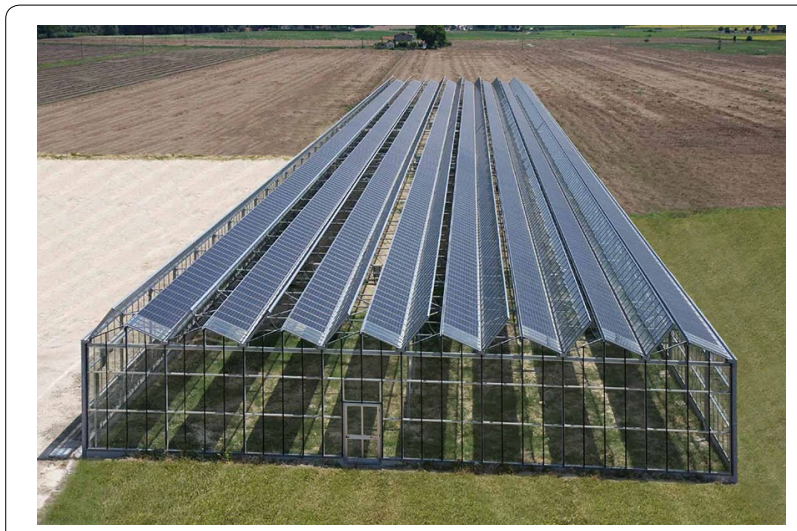

Fig. 5 Photovoltaic tower in Recanati (Source: Blogo)

The hydroelectric plants which have been built since the incentives were introduced are characterized by medium and small sizes and run-of-river systems. That is because there are no large basins left to build dams, as most of them have already been exploited and in more than 30 years much more restrictive landscape and environmental regulations have been adopted. This has generally led to a limited landscape impact both in mountain areas, also resulting from an improvement in landscape design, and along river banks in flat areas (see Fig. 6).

In order to encourage the exploitation of small water jets, the economic contributions are inversely proportional to the power of the hydroelectric plant. This has indirectly favoured solutions with less efficiency and greater impact. For example, it has often been chosen not to fully exploit the available flow rates or to limit production to shorter periods of time than water availability would allow, maximizing the economic performance of the plant to the detriment of electric power generation. In addition, the introduction of incentives to build new plants has made it less convenient to carry out repowering operations of existing plants. As a result, existing plants have become less efficient in favour of new

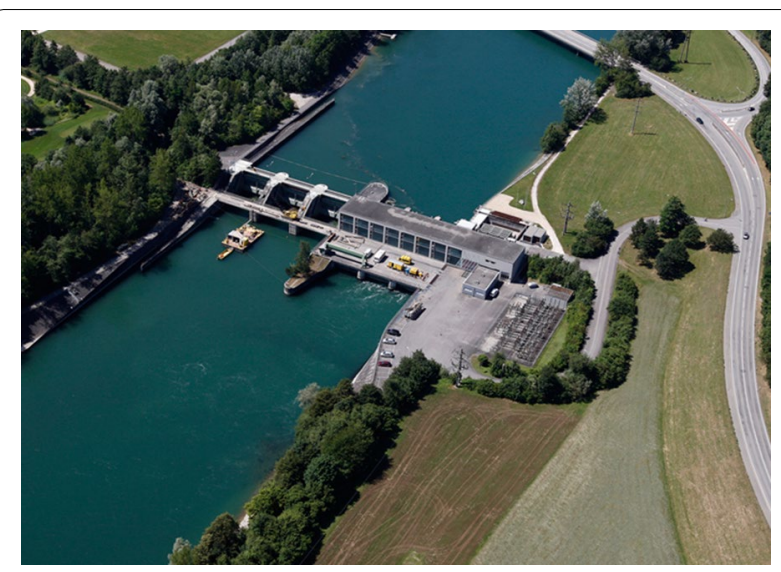

Fig. 6 River hydropower station running on the River Tiber (Source: Ministry of the Environment)

interventions on still unexploited water resources. Crucial factors in choosing between different water energy uses are the preservation of eco-systemic continuity, minimizing interruptions in the water body with the same level of hydroelectric potential exploitation; a low impact on the landscape, limiting the number and size of buildings and equipment and improving their architectural quality; and the minimization of the construction of new plants, favouring the repowering of existing ones.

Biomass energy is produced from organic materials. It can be used directly as fuel or transformed into other substances (solid, liquid or gaseous) which are easier to use in energy plants (Consorzio italiano biogas 2012).

From the point of view of the effects on the landscape it is necessary to distinguish the production phase, which essentially concerns the cultivation and harvesting of biomasses, from the use phase, regarding all the infrastructures and plants used to produce energy.

From the point of view of the production we can distinguish between two types of biomass.

The first concerns the biomass consisting of forest residues and crops for human or animal feeding of waste materials produced by the wood processing industry (wood chips, wood sawdust, etc.), livestock and markets, and of urban solid waste. Using this type of biomass does not involve significant changes in the landscape as it is grafted onto existing activities and favours the closing of the resource cycle.

The second type concerns those biomasses specially cultivated to produce energy and characterized by vegetable species with a favourable balance between consumed and produced energy (such as thistle, broom, black locust, poplar, etc.). They are mainly used in agricultural areas and characterize the landscape for chromatically different crops as compared with existing ones 


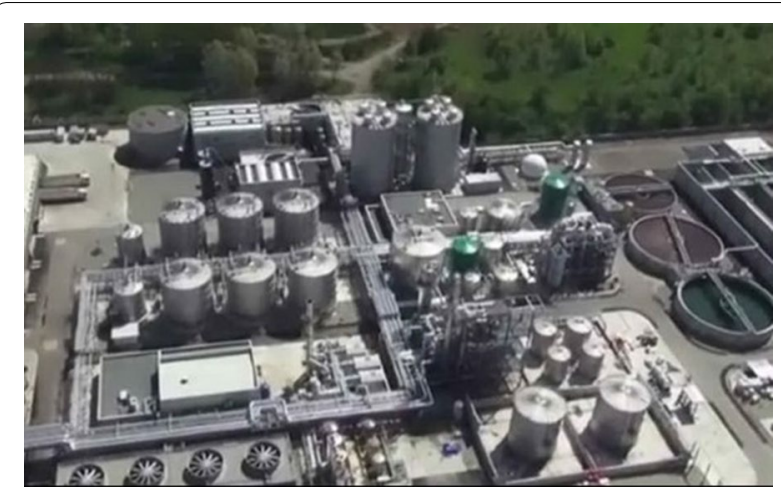

Fig. 7 Plant for bioethanol production in Crescentino (VC) (Source: Unione Sarda.it)

and for wooded areas with a strong artificial appearance due to their rigid and regular planting and with a considerable arboreal mass. Thus biomass cultivation takes away large agricultural areas intended for food production, although this activity does not damage rural ecosystems and, in some cases, improves them, since the cultivated tree species can function also as windbreak, phyto-depuration and anti-erosion tools. In addition, the new poplar plantations in the agricultural sector have a preservative character as they harmonize with the context and constitute landmarks.

Among the different types of plants that use or transform biomass, only medium and large ones significantly alter the landscape. Generally they are made up of district heating systems, whose main purpose is the generation and distribution of thermal energy for domestic use as well as the generation of electricity and whose power is between 3 and $20 \mathrm{MW}$, and thermal energy plants powered with wood or a mixture of biomass and waste-derived fuels (CDRs), designed for the production of electricity and characterized by a power greater than $20 \mathrm{MW}$. In addition to energy production plants also biomass processing and refining plants (see Fig. 7) should be considered, although these are often located in the same sites of the energy-producing plants when they are the latter's main suppliers.

Biomass district heating systems have a considerable size and are often located in industrial zones at the edge of urban areas, so their impact on the landscape is mainly related to the quality of the architectural design (see Fig. 8). More problematic is the relationship between the landscape and thermoelectric power plants, since they are larger than previous plants and do not need to be located near urban areas (as they do not provide users with heat) but rather near water courses for cooling. The effects produced on the landscape by larger plants located in open areas are similar to

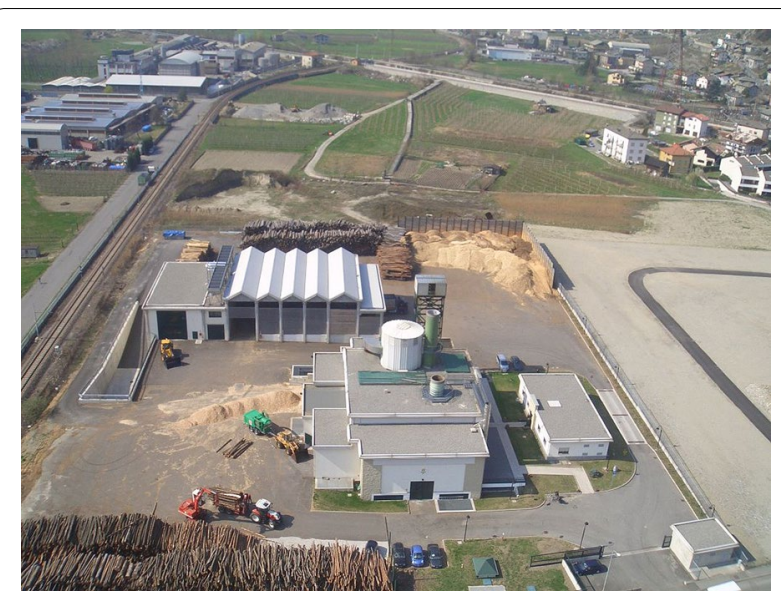

Fig. 8 Biomass district heating plant of Tirano (Source: Alta Rezia News)

those generated by fossil-fuelled thermoelectric power plants, meaning that their impact is strongly influenced by their location and design.

Following the introduction of special incentives, in recent years there has been a significant increase in the number of plants producing both electricity from biogas and biomethane from the anaerobic digestion of organic waste and by-products of the agro-industry. The biomethane, which is released into the grid or used as a fuel for road haulage, is obtained through mediumsized plants located near biogas production plants. Again, the effect on the landscape is strongly influenced by the location of these plants in industrial or rural areas.

\section{Authors' contributions}

MM and RA have decided together about the contents and characters of the paper and have verified all the paper. RA has deeped the acts, regulations, directives about the incentives to renewable energy sources and he has writen the first 2 chapters. MM has explored the characters of energy landscapes influenced by the incentives and he has written the third paragraph. Both authors read and approved the final manuscript.

\section{Author details}

${ }^{1}$ CCRR-Lab, DAStU—Politecnico di Milano, Milan, Italy. ${ }^{2}$ Politecnico di Milano, Milan, Italy.

\section{Competing interests}

The authors declare that they have no competing interests.

\section{Availability of data and materials}

Not applicable.

\section{Consent for publication}

Not applicable.

Ethics approval and consent to participate Not applicable. 


\section{Funding}

Not applicable.

\section{Publisher's Note}

Springer Nature remains neutral with regard to jurisdictional claims in published maps and institutional affiliations.

Received: 30 July 2018 Accepted: 17 October 2018

Published online: 29 October 2018

\section{References}

Allred B, Smith K, Twidwell D et al (2015) Ecosystem services lost to oil and gas in North America. Science 348(6233):401-402

Ardolino D (2009) The public intervention in energy sector: support mechanism to renewable energy sources. Innovazione \& Diritto, n. 1/2009

Baldescu I, Barion F (2011) Fotovoltaico: prontuario per la valutazione del suo inserimento nel paesaggio e nei contesti architettonici. Ministero per i beni e le attività culturali, Direzione Veneto, Rome

Battistella A (2010a) I nuovi paesaggi dell'energia. www.nextville.it

Battistella A (2010b) Trasformare il paesaggio. Energia eolica e nuova estetica del territorio. Edizioni ambiente, Milano

Campbell C, Denholm P, Margolis R, Heath G (2013) Land-use requirements for solar power plants in the United States, U.S. Department of Energy Efficiency \& Renewable Energy, Technical Report NREL/TP-6A20-56290, June 2013
Consorzio italiano biogas (a cura di) (2012) Il biogas che fa bene al paese. Guida ad una fonte rinnovabile virtuosa per l'ambiente. Speciale tecnico, QualEnergia.it

De Pascali P (2008) Città ed energia: la valenza energetica dell'organizzazione insediativa. Franco Angeli, Milano

Magoni M (2010) Energia e paesaggio: tra passato, presente e prossimo futuro, in «Trasporti e cultura», n. 26, gennaio-aprile 2010

Manna C, Fidanza A, Leonardi M et al (2010) Le fonti rinnovabili 2010: ricerca e innovazione per un futuro low-carbon. ENEA, Roma

Marchigiani E, Prestamburgo S (2010) Energie rinnovabili e paesaggi. Strategie e progetti per la valorizzazione delle risorse territoriali. Franco Angeli, Milano

Socco C, Cavaliere A, Guarini SM, Rosa E (2007) La valutazione del carattere del paesaggio. Workingpaper P04/07, Osservatorio Città Sostenibili, Dipartimento Interateneo Territorio, Politecnico e Università di Torino

Serra E (2011) L'energia nella definizione del progetto di architettura e paesaggio: le potenzialità delle FER, Università degli Studi di Cagliari, Facoltà di Architettura, Dottorato di Ricerca in Architettura, Anno 2010-2011, Tutor CESARINA SIDDI

U.S. Department of Energy (2015) Wind vision: a new era for wind power in the United States. Office of Scientific and Technical Information, April 2015

\section{Submit your manuscript to a SpringerOpen ${ }^{\odot}$ journal and benefit from:}

- Convenient online submission

- Rigorous peer review

- Open access: articles freely available online

- High visibility within the field

- Retaining the copyright to your article

Submit your next manuscript at $\boldsymbol{\nabla}$ springeropen.com 